\title{
3C syndrome
}

INSERM

\section{Source}

INSERM. (1999). Orphanet: an online rare disease and orphan drug data base. $\underline{3 C}$ syndrome. ORPHA:7

Cranio-cerebello-cardiac (3C) syndrome is a rare multiple congenital anomalies syndrome characterized by craniofacial (prominent occiput and forehead, hypertelorism, ocular coloboma, cleft palate), cerebellar (Dandy-Walker malformation, cerebellar vermis hypoplasia) and cardiac (tetralogy of Fallot, atrial and ventricular septal defects) anomalies (see these terms). 